\title{
A Simple and Efficient Protocol for Plant Regeneration and Genetic Transformation of Tomato cv. Micro-Tom from Leaf Explants
}

\author{
Abraham Cruz-Mendívil \\ Maestría en Ciencia y Tecnología de Alimentos, y Programa Regional de \\ Doctorado en Biotecnología, Facultad de Ciencias Químico-Biológicas, \\ Universidad Autónoma de Sinaloa, Av. de las Américas y Josefa Ortiz S/N, \\ Culiacán, Sin., México 80030
}

\section{Javier Rivera-López}

Departamento de Ingeniería Química, Bioquímica y Biología, Instituto Tecnológico de Los Mochis, Boulevard Juan de Dios Bátiz y 20 de Noviembre S/N, Los Mochis, Sin., México 81200

\section{Lourdes J. Germán-Báez}

Maestría en Ciencia y Tecnología de Alimentos, y Programa Regional de Doctorado en Biotecnología, Facultad de Ciencias Químico-Biológicas, Universidad Autónoma de Sinaloa, Av. de las Américas y Josefa Ortiz S/N, Culiacán, Sin., México 80030

\section{Melina López-Meyer}

Centro Interdisciplinario de Investigación para el Desarrollo Integral Regional del IPN, Unidad Sinaloa, Boulevard Juan de Dios Bátiz \#250, Guasave, Sin., México 81101

\section{Sergio Hernández-Verdugo, José A. López-Valenzuela, Cuauhtémoc Reyes-Moreno, and Angel Valdez-Ortiz ${ }^{\mathbf{1}}$ \\ Maestría en Ciencia y Tecnología de Alimentos, y Programa Regional de Doctorado en Biotecnología, Facultad de Ciencias Químico-Biológicas, Universidad Autónoma de Sinaloa, Av. de las Américas y Josefa Ortiz S/N, Culiacán, Sin., México 80030}

Additional index words. Solanum lycopersicum, shoot-forming capacity, fully developed plantlets, Agrobacterium tumefaciens, gusA expression, transgenic plants

\begin{abstract}
A simplified protocol to obtain transgenic tomato plants was established. The effects of culture media composition and Agrobacterium concentration were evaluated. The highest shoot-forming capacity index (5.6) was observed when leaf explants were cultured for 6 weeks with $2 \mathrm{mg} \cdot \mathrm{L}^{-1}$ zeatin, $0.1 \mathrm{mg} \cdot \mathrm{L}^{-1}$ indoleacetic acid, and $300 \mathrm{mg} \cdot \mathrm{L}^{-1}$ timentin. Shoot elongation and root formation were performed in one step on growth regulator-free media. The highest percentage $(82 \%)$ of fully developed plantlets was obtained when shoots were cultured for 4 weeks with $0.5 \times$ Murashige and Skoog (MS) media and $15 \mathrm{~g} \cdot \mathrm{L}^{-1}$ sucrose. A $100 \%$ of plant survival rate was observed after 4 weeks of being transplanted to ex vitro conditions followed by fruit production (15 fruits/plant) after 2 more weeks. Transient expression of $\beta$-glucuronidase was visualized in $100 \%$ of the leaf explants infected with Agrobacterium at an $\mathrm{OD}_{600}=0.5$ and cocultured for $48 \mathrm{~h}$ with $2 \mathrm{mg} \cdot \mathrm{L}^{-1}$ benzylaminopurine, $0.1 \mathrm{mg} \cdot \mathrm{L}^{-1}$ naphthaleneacetic acid, and $100 \mu \mathrm{M}$ acetosyringone. Stable transformation was confirmed by histochemical glucuronidase assay and polymerase chain reaction (PCR) analysis with a total efficiency of $19.1 \%$. The complete protocol, from shoot induction to fruit production of soil-adapted transgenic plants can be accomplished in only 4 months, and it seems to be very useful for both micropropagation and genetic transformation purposes.
\end{abstract}

Tomato (Solanum lycopersicum) is the second most important horticultural crop worldwide with an annual production close to 130 million tons in 2009 with Mexico occupying tenth place in production and first place in exports (FAOSTAT, 2011). As a result of its importance as a human food source, and biological features such as relatively small genome $(950 \mathrm{Mb})$ and transformability, tomato has long served as a model system for plant genetics, developmental, pathology, and physiology studies, which had resulted in the accumulation of substantial information regarding its biology (Dan et al., 2006).

Among the existing tomato genotypes, the cultivar Micro-Tom is considered a model system because of its unique characteristics such as small size ( 15 to $20 \mathrm{~cm}$ ), ability to grow in high densities (greater than 1357 plants $/ \mathrm{m}^{2}$ ), and short life cycle (90 d). These features allow the setting of experiments in confined and controlled environments, which meet with biosafety regulations for genetically modified organisms. In addition, tomato cv. Micro-Tom differs from standard tomato cultivars in only two major genes (dwarf and miniature); therefore, any mutation or transgene can be conveniently studied in its genetic background (Emmanuel and Levy, 2002; Meissner et al., 1997).

The generation of transgenic plants involves the development of plant tissue culture and gene transfer procedures, in which the lack of efficient regeneration protocols is the limiting step (Herrera-Estrella et al., 2004). In tomato, plant regeneration is accomplished through organogenesis and it is affected by several factors such as genotype, explant characteristics (type, size, age, and orientation), media composition (growth regulators, carbon source, minerals, and vitamins), and environmental conditions (irradiation, photoperiod, and temperature) (Bhatia et al., 2004). Regarding gene transfer systems in tomato, the method most commonly used is mediated by Agrobacterium tumefaciens, and although the first transformation protocol was reported in 1986 (McCormick et al., 1986), this procedure is still far from being a routine technique. Tomato gene transfer is affected by several factors such as Agrobacterium strain and concentration, infection method and duration, use of feeder layers, acetosyringone, and growth regulators during pre- and coculture as well as temperature and duration of pre- and coculture (Frary and Van Eck, 2004).

High genetic transformation efficiencies ranging from $10 \%$ to $56 \%$ have been previously reported in tomato cv. Micro-Tom (Dan et al., 2006; Park et al., 2003; Qiu et al., 2007; Sun et al., 2006); however, most of these protocols are tedious and time-consuming as a result of laborious Agrobacterium preparation, use of feeder layers, complex media formulations, and numerous subcultures. The aim of the present study was to establish a simple and efficient protocol to obtain transgenic tomato plants of cv. Micro-Tom, including an optimized ex vitro acclimatization procedure with high plant survival rate and fruit yield.

\section{Materials and Methods}

Plant material. Seeds of tomato (Solanum lycopersicum) cv. Micro-Tom were acquired from a commercial source (Tomato Growers Supply Co.). The seeds were surface-sterilized by immersion for $1 \mathrm{~min}$ in $70 \%(\mathrm{v} / \mathrm{v})$ ethanol followed by $30 \mathrm{~min}$ in $25 \%$ (v/v) commercial bleach and five rinses with sterile distilled water. Sterilized seeds were cultured on Magenta boxes with $0.5 \times$ MS (Murashige and Skoog, 
1962) and $15 \mathrm{~g} \cdot \mathrm{L}^{-1}$ sucrose and kept in the dark at $25^{\circ} \mathrm{C}$ for $5 \mathrm{~d}$ followed by incubation under controlled light conditions (16:8-h photoperiod and $80 \mu \mathrm{mol} \cdot \mathrm{m}^{-2} \cdot \mathrm{s}^{-1}$ irradiance) in a growth chamber, KBW 400 (BINDER, Germany). All media were solidified with $8 \mathrm{~g} \cdot \mathrm{L}^{-1}$ agar, and the $\mathrm{pH}$ was adjusted to 5.8 before autoclaving at $121{ }^{\circ} \mathrm{C}$ for $15 \mathrm{~min}$. Plant growth regulators and antibiotics were added after media were cooled to $55^{\circ} \mathrm{C}$.

Shoot induction. The effect of culture media supplemented with benzylaminopurine (Rao et al., 2005), zeatin (Dan et al., 2006) and timentin (Costa et al., 2000) were evaluated. Leaf explants $\left(0.5 \mathrm{~cm}^{2}\right)$ from 4-week-old in vitro plantlets were placed in abaxial orientation (downside of the leaf touching the medium) on petri dishes with four shoot induction media (SIM) containing $1 \times \mathrm{MS}, 30 \mathrm{~g} \cdot \mathrm{L}^{-1}$ sucrose, and $0.1 \mathrm{mg} \cdot \mathrm{L}^{-1}$ indoleacetic acid (IAA) with the following differences: (SIM1) $2 \mathrm{mg} \cdot \mathrm{L}^{-1}$ benzylaminopurine (BAP); (SIM2) $2 \mathrm{mg} \cdot \mathrm{L}^{-1}$ $\mathrm{BAP}+300 \mathrm{mg} \cdot \mathrm{L}^{-1}$ timentin (TM); (SIM3) $2 \mathrm{mg} \cdot \mathrm{L}^{-1}$ zeatin (ZT); and (SIM4) $2 \mathrm{mg} \cdot \mathrm{L}^{-1}$ $\mathrm{ZT}+300 \mathrm{mg} \cdot \mathrm{L}^{-1} \mathrm{TM}$. Explants were kept in a growth chamber for 6 weeks under the same conditions described previously, and one subculture to fresh medium was performed on the third week. The percentage of explants with shoots and number of shoots per explant were recorded after 6 weeks of culture. Additionally, the shoot-forming capacity (SFC) index was calculated according to Martínez-Pulido et al. (1992) as follows: SFC index $=[(\%$ explants with shoots $) \times$ (mean number of shoots per explant)]/100.

Shoot elongation/rooting. The elongation and rooting of shoots were performed in one step (Qiu et al., 2007) on growth regulator-free media (Sun et al., 2006), and the effects of MS salts and sucrose were evaluated. Differentiated shoots (greater than $1 \mathrm{~cm}$ long) were cultured on baby food jars with four elongation/ rooting media (ERM) with the following differences: (ERM1) $0.5 \times \mathrm{MS}+15 \mathrm{~g} \cdot \mathrm{L}^{-1} \mathrm{su}-$ crose; (ERM2) $0.5 \times \mathrm{MS}+30 \mathrm{~g} \cdot \mathrm{L}^{-1}$ sucrose; (ERM3) $1 \times \mathrm{MS}+15 \mathrm{~g} \cdot \mathrm{L}^{-1}$ sucrose; and (ERM4) $1 \times \mathrm{MS}+30 \mathrm{~g} \cdot \mathrm{L}^{-1}$ sucrose. Explants were kept in a growth chamber for 4 weeks under the same conditions described previously, and no subcultures to fresh medium were carried out. Plantlet height, number of leaves, and root length were recorded after 4 weeks. In this study, we established a criterion for the selection of fully developed plantlets (FDPs), which was defined as plantlets with at least $5 \mathrm{~cm}$ in height, 15 leaves, and $10 \mathrm{~cm}$ in root length. This strategy allowed to select plantlets with higher chances of survival during the transfer to ex vitro conditions.

\footnotetext{
Received for publication 14 June 2011. Accepted for publication 28 Sept. 2011.

This work was supported by grants from Consejo Nacional de Ciencia y Tecnología (CONACyT, 58791) and Programa de Fomento y Apoyo a Proyectos de Investigación-Universidad Autónoma de Sinaloa (PROFAPI-UAS, 2009/181).

${ }^{1}$ To whom reprint requests should be addressed; e-mail angelvaldezortiz@yahoo.com.mx.
}

Ex vitro acclimatization. FDPs were removed from in vitro vessels and gently washed with sterile water to remove any remaining medium from the roots followed by immersion in $1 \mathrm{~g} \cdot \mathrm{L}^{-1}$ benomyl solution for $30 \mathrm{~s}$. Then, plants were transferred to pots containing sterile vermiculite and covered with transparent polyethylene cups to ensure a high-humidity environment. Covers were sequentially perforated every other day and completely removed after 2 weeks. Plants were watered with $20 \mathrm{~mL}$ of $0.5 \times$ MS solution every $3 \mathrm{~d}$ and kept under controlled conditions in a growth room $\left(25^{\circ} \mathrm{C}, 65 \%\right.$ relative humidity, $16: 8$-h photoperiod, $40 \mu \mathrm{mol} \cdot \mathrm{m}^{-2} \cdot \mathrm{s}^{-1}$ irradiance). Survival data were recorded after 4 weeks.

Bacterial strain and plasmid. The binary vector pCAMBIA2301 (GenBank AF234316.1) was cloned into Agrobacterium tumefaciens strain EHA105 by electroporation (800 V) using an electroporator model 2510 (Eppendorf). The vector pCAMBIA2301 contains a modified $\beta$-glucuronidase (gusA) gene with an intron (from catalase gene) and the neomycin phosphotransferase II (nptII) gene, both under the regulation of the constitutive promoter CaMV35S.

Gene transfer. The effects of Agrobacterium concentration and culture media on tomato genetic transformation were evaluated. A simplified Agrobacterium preparation was carried out according to Valdez-Ortiz et al. (2007), with some modifications. $A$. tumefaciens EHA105:pCAMBIA2301 cells were streaked in petri dishes with LuriaBertani medium amended with $50 \mathrm{mg} \cdot \mathrm{L}^{-1}$ kanamycin $(\mathrm{KM})$ and incubated in the dark at $28{ }^{\circ} \mathrm{C}$ for $48 \mathrm{~h}$. After that, A. tumefaciens cells were scraped out of the dish and suspended in $30 \mathrm{~mL}$ of infection medium (1x $\mathrm{MS}, 30 \mathrm{~g} \cdot \mathrm{L}^{-1}$ sucrose) until the desired concentration $\left(\mathrm{OD}_{600}=0.2,0.5,0.8\right)$ was achieved. Then, $100 \mu \mathrm{M}$ acetosyringone (AS) was added, and bacterial suspensions were incubated at $28{ }^{\circ} \mathrm{C}, 200 \mathrm{rpm}$, for $4 \mathrm{~h}$ before infection.

The effect of culture media supplemented with ZT and IAA (Qiu et al., 2007) or BAP and naphthaleneacetic acid (NAA) (Park et al., 2003) was evaluated during the pre-culture and coculture steps. Leaf explants $\left(0.5 \mathrm{~cm}^{2}\right)$ obtained from 4-week-old plantlets were precultured in abaxial orientation on petri dishes with two pre-culture media (PCM) containing $1 \times \mathrm{MS}, 30 \mathrm{~g} \cdot \mathrm{L}^{-1}$ sucrose, $100 \mu \mathrm{M}$ AS, with the following differences: (PCM1) $2 \mathrm{mg} \cdot \mathrm{L}^{-1} \mathrm{ZT}+$ $0.1 \mathrm{mg} \cdot \mathrm{L}^{-1} \mathrm{IAA}$, and (PCM2) $1 \mathrm{mg} \cdot \mathrm{L}^{-1} \mathrm{BAP}+$ $0.1 \mathrm{mg} \cdot \mathrm{L}^{-1} \mathrm{NAA}$. Explants were incubated at $25^{\circ} \mathrm{C}, 16: 8-\mathrm{h}$ photoperiod, $80 \mu \mathrm{mol} \cdot \mathrm{m}^{-2} \cdot \mathrm{s}^{-1}$ irradiance for $48 \mathrm{~h}$. After that, explants were infected with $A$. tumefaciens suspensions for 10 min with occasional agitation. Finally, explants were cocultured in adaxial orientation (upside of the leaf touching the medium) in the same PCM plates, but now with sterile filter paper above the media to avoid Agrobacterium overgrowth, and were incubated in the dark at $25^{\circ} \mathrm{C}$ for $48 \mathrm{~h}$.

Histochemical glucuronidase assay. Cocultured explants were washed with sterile distilled water and subjected to histochemical glucuronidase (GUS) assay according to Jefferson (1987). The explants were immersed in a staining solution that contained the substrate X-Gluc (GUSS-1KT; Sigma, St. Louis, MO) and were incubated in the dark at $37{ }^{\circ} \mathrm{C}$ for $24 \mathrm{~h}$. Then, the explants were rinsed several times with absolute ethanol to remove chlorophyll, and gusA expression was visualized as indigo blue spots using a digital microscope DM143 (Motic). Gene transfer efficiency was measured as percentage of explants with gusA expression.

Molecular analysis. Total genomic DNA was isolated from young leaves of putative transformed and wild-type plants using Plant DNAzol (Invitrogen) and further subjected to PCR analysis to detect the presence of gus A with a predicted fragment size of $982 \mathrm{bp}$. Plasmid pCAMBIA2301 was used as a positive control. Specific primers for gusA were used: forward 5'-CCGTGGTGACGCATG TCGCGCAAGAC-3' and reverse 5' -CGG CGTGGATACGTTAGCCGGGCTGCAC TC-3'. For additional confirmation of transgenic integration, a segment of $341 \mathrm{bp}$ of the CaMV 35S promoter was amplified using the primers: forward 5'- GATACAGTCTCA GAAGACCAAAGGGC-3' and reverse 5' GAGGAAGGGTCTTGCGAAGGATAGT GGG-3' . PCR was carried out in $20-\mu \mathrm{L}$ reaction volume containing $0.2 \mathrm{~mm}$ of each $\mathrm{dNTP}, 0.2 \mu \mathrm{M}$ of each oligonucleotide, $3 \mathrm{U}$ Taq polymerase, $1.5 \mathrm{~mm}$ of $\mathrm{MgCl}_{2}$, and $100 \mathrm{ng}$ of sample DNA. The reaction mixtures were subjected to the following amplification conditions: 2 min at $94{ }^{\circ} \mathrm{C}, 25$ cycles of $1 \mathrm{~min}$ at $94{ }^{\circ} \mathrm{C}, 2 \mathrm{~min}$ at $58{ }^{\circ} \mathrm{C}, 2 \mathrm{~min}$ at $72{ }^{\circ} \mathrm{C}$, and finally $5 \mathrm{~min}$ at $72{ }^{\circ} \mathrm{C}$. The amplified fragments were separated by electrophoresis on $1 \%(\mathrm{w} / \mathrm{v})$ agarose gels stained with ethidium bromide and fluorescence visualized under ultraviolet light.

Statistical analysis. All experiments were conducted as a completely randomized design. Five replicates per treatment were used in each experiment. A replicate consisted of a petri dish with 10 leaf explants for the shoot induction experiment, a baby food jar with five shoots for the elongation/rooting experiment, and a petri dish with five leaf explants for the gene transfer experiment. Data were subjected to analysis of variance and treatment means were compared using the Fisher's least significant difference test $(P \leq 0.05)$ using STATGRAPHICS Plus 5.1 software.

\section{Results and Discussion}

Shoot induction. Leaf explants (Fig. 1A) were able to develop green compact calli and small shoots (Fig. 1B) after 4 weeks of culture in all the tested media. Differentiated shoots were obtained after 6 weeks of culture (Fig. 1C), and significant differences ( $P \leq$ $0.05)$ were observed among treatments $(\mathrm{Ta}$ ble 1). The percentage of explants with shoots ranged from $28.1 \%$ to $69.2 \%$, and the number of shoots per explant from 2.8 to 7.8 ; meanwhile, the SFC index varied from 0.8 to 5.6 (Table 1). According to Vanegas et al. 


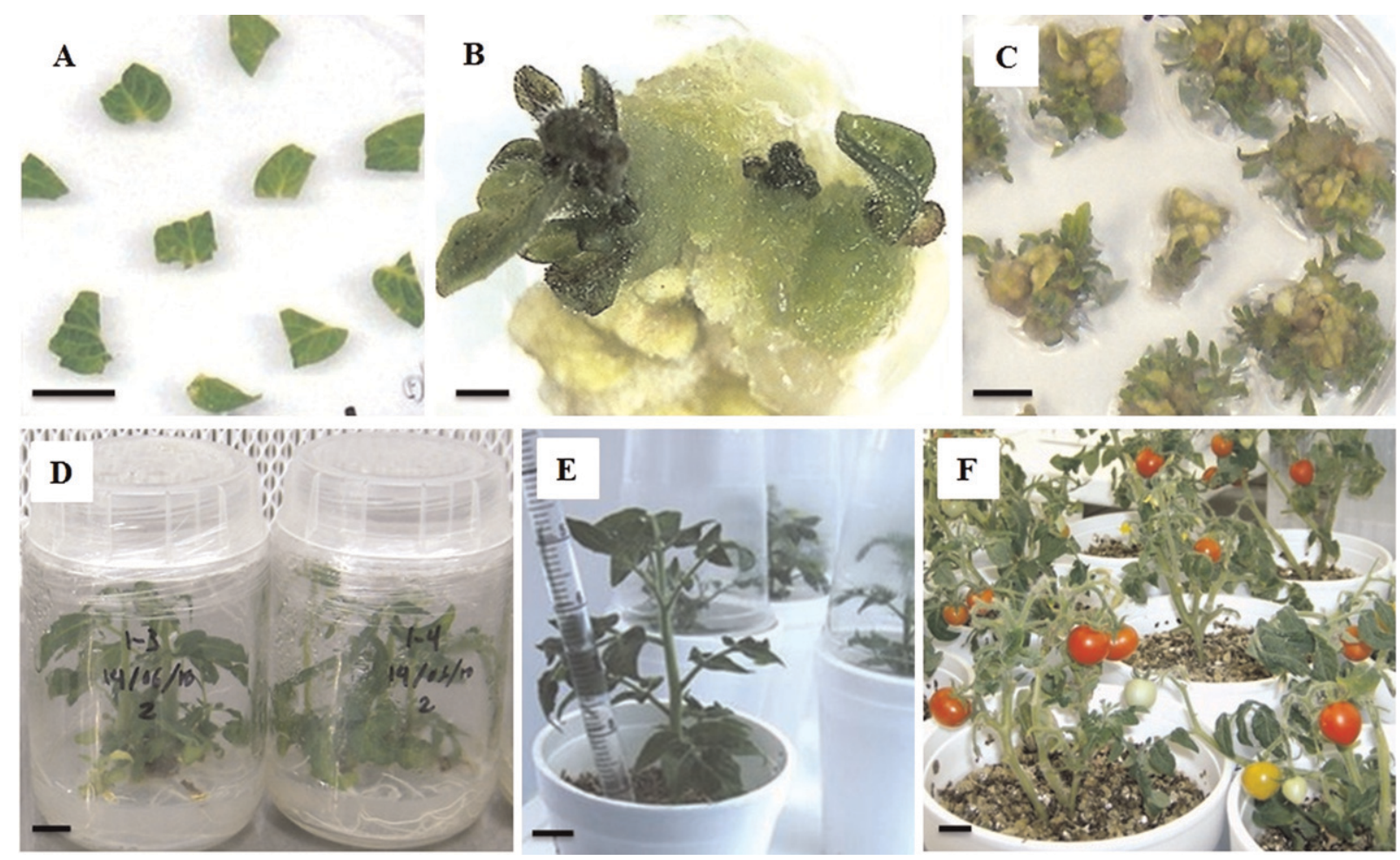

Fig. 1. In vitro regeneration and ex vitro acclimatization of tomato. (A) Leaf explants. (B) Calli and shoot induction after 4 weeks in SIM4. (C) Differentiated shoots after 6 weeks in SIM4. (D) Fully developed plantlets after 4 weeks in ERM1. (E) Ex vitro acclimatization of plantlets. (F) Fruit production. Bars $=1 \mathrm{~cm}$, except for $\mathbf{B}$ in which it is $0.1 \mathrm{~cm}$. SIM = shoot induction media; ERM = elongation/rooting media.

Table 1. Effect of culture media on shoot induction from tomato leaf explants.

\begin{tabular}{lcccccc}
\hline $\begin{array}{l}\text { Culture } \\
\text { media }\end{array}$ & $\begin{array}{c}\text { BAP } \\
\left(\mathrm{mg} \cdot \mathrm{L}^{-1}\right)\end{array}$ & $\begin{array}{c}\text { ZT } \\
\left(\mathrm{mg} \cdot \mathrm{L}^{-1}\right)\end{array}$ & $\begin{array}{c}\text { TM } \\
\left(\mathrm{mg} \cdot \mathrm{L}^{-1}\right)\end{array}$ & $\begin{array}{c}\text { Explants with } \\
\text { shoots }(\%)\end{array}$ & $\begin{array}{c}\text { Number of shoots } \\
\text { per explants }\end{array}$ & SFC index \\
\hline SIM1 & 2 & - & - & $28.1 \mathrm{c}$ & $2.8 \mathrm{~b}$ & $0.8 \mathrm{c}$ \\
SIM2 & 2 & - & 300 & $52.9 \mathrm{ab}$ & $4.9 \mathrm{ab}$ & $3.1 \mathrm{~b}$ \\
SIM3 & - & 2 & - & $44.8 \mathrm{bc}$ & $6.4 \mathrm{a}$ & $2.2 \mathrm{bc}$ \\
SIM4 & - & 2 & 300 & $69.2 \mathrm{a}$ & $7.8 \mathrm{a}$ & $5.6 \mathrm{a}$ \\
\hline
\end{tabular}

Data recorded after 6 weeks of culture. Means with different letters within a column indicate significant differences (least significant difference, $P \leq 0.05$ ).

$\mathrm{BAP}=$ benzylaminopurine; $\mathrm{ZT}=$ zeatin; $\mathrm{TM}=$ timentin; $\mathrm{SFC}=$ shoot-forming capacity; $\mathrm{SIM}=$ shoot induction media.

(2002), the percentage of explants with shoots represents the response capacity of the tissue to the medium, and the number of shoots per explant represents the capacity of the explants to produce shoots; thus, the combination of these values in the SFC index gives a better idea about the optimal conditions for plant regeneration.

As observed in Table 1, higher values of shoot induction were obtained in general when ZT (SIM3) was used instead of BAP (SIM1), and significant differences $(P \leq$ 0.05 ) were found in the number of shoots per explants. Some studies have shown that a better regeneration response in tomato is achieved with ZT in comparison with BAP (Gubis et al., 2004; Park et al., 2003), which could be explained, in part, by the fact that ZT is a natural cytokinin, whereas BAP is synthetic. On the other hand, when TM was added to the medium, a synergistic effect of both cytokinins was observed. The addition of TM in SIM2 and SIM4 significantly increased $(P \leq 0.05)$ the percentage of explants with shoots and the SFC index in comparison with the media containing BAP or ZT alone (SIM1 and SIM3). TM is a mixture of ticarcillin (penicillin derivative) and clavulanic acid ( $\beta$-lactamase inhibitor) with activity against many Gram-negative bacteria including Agrobacterium; in addition, a positive effect of TM on tomato organogenesis has been reported (Costa et al., 2000; Ling et al., 1998), which may be the result of the release of auxin-like compounds during hydrolysis, increasing the regeneration response of explants as observed in the present study.

The most efficient regeneration treatment was SIM4, because it resulted in the highest SFC index (5.6) with significant differences $(P \leq 0.05)$ when compared with the other three media (Table 1). To our knowledge, there are no studies in tomato in which the SFC index has been used to evaluate shoot induction efficiency; however, it has been successfully used in other plant species for the optimization of regeneration protocols. For instance, Vanegas et al. (2002) reported a SFC index of 1.39 in leaf explants of Tagetes erecta cultured with BAP $(13.3 \mu \mathrm{M})$, García-Saucedo et al. (2005) obtained a SFC index of 3.4 in cladode explants of Opuntia ficus-indica cultured with BAP $(0.5 \mu \mathrm{M})$, and Rivera-López (2011) observed a SFC index of 1.44 in leaf explants of Solanum tuberosum cultured with ZT (2 $\left.\mathrm{mg} \cdot \mathrm{L}^{-1}\right)$ and NAA $\left(0.02 \mathrm{mg} \cdot \mathrm{L}^{-1}\right)$.

Shoot elongation/rooting. Development of roots and new leaves was observed after 2 weeks in all media (Fig. 1D) followed by the formation of FDP after 4 weeks of culture Leaf number ranged from 9.2 to 21.3 , plantlet height from 2.3 to $4.8 \mathrm{~cm}$, root length from 3.5 to $15.8 \mathrm{~cm}$, and the percentage of FDP from $32 \%$ to $82 \%$ (Table 2). ERM1 and ERM4 treatments rendered significantly higher values $(P \leq 0.05)$ than ERM2 and ERM3 in all responses (leaf number, plantlet height, root length, percent FDP). Interestingly, ERM1 and ERM4 had the same proportion of MS salts and sucrose, which suggests that the balance between these components is more important than their concentrations. To reduce costs, the use of ERM1 is recommended.

In the present work, the elongation and rooting of shoots were achieved on growth regulator-free media in a single step with no subcultures, which makes this protocol simpler and easier than others previously reported for the Micro-Tom cultivar (Dan et al., 2006; Sun et al., 2006), in which two different media were used for shoot elongation and rooting steps. There are some reports that describe higher rooting rates in tomato shoots with auxin-supplemented medium in comparison with auxin-free medium (Dan et al., 2006; 
Rao et al., 2005); nevertheless, it is well established that tomato contains high levels of endogenous auxins; therefore, exogenous growth regulators are not required for rooting (Mensuali-Sodi et al., 1995). On the other hand, we considered that the percentage of rooting by itself is not enough as an indicator of the plantlet's development, and it is necessary to consider other parameters such as root length, leaf number, and plantlet height. In this sense, the use of a criterion for the selection of FDP (see "Materials and Methods") is a more proper strategy to measure the shoot elongation/rooting response, because it allows a more objective and realistic evaluation of the considered variables. In addition, selection of FDP increases the chances of obtaining higher survival efficiencies during the ex vitro acclimatization of plantlets.
Using the best treatments for shoot induction and rooting, and considering that $\approx 20$ leaf explants can be obtained from each 4-week-old plantlet, it is possible to obtain up to 90 FDPs in 10 weeks, making this a high-efficiency protocol.

Ex vitro acclimatization. In vitro cultured plantlets are subjected to special conditions (high humidity, low gas exchange, low irradiance), which could induce disturbances in plant development and photosynthesis performance; therefore, when plantlets are transferred to ex vitro conditions (greenhouse or field), an acclimatization period is required to correct any abnormality (Pospíšilová et al., 1999). On preliminary tests, three different substrates (garden soil, peatmoss, vermiculite), and doses of ferti-irrigation $(0.5,1.0$, $1.5 \times \mathrm{MS})$ were evaluated. High fungal con-

Table 2. Effect of culture media on shoot elongation and root formation in tomato.

\begin{tabular}{lcccccc}
\hline $\begin{array}{l}\text { Culture } \\
\text { media }\end{array}$ & $\begin{array}{c}\text { MS salts } \\
(\times)\end{array}$ & $\begin{array}{c}\text { Sucrose } \\
\left(\mathrm{g} \cdot \mathrm{L}^{-1}\right)\end{array}$ & $\begin{array}{c}\text { Number of } \\
\text { leaves }\end{array}$ & $\begin{array}{c}\text { Plantlet ht } \\
(\mathrm{cm})\end{array}$ & $\begin{array}{c}\text { Root length } \\
(\mathrm{cm})\end{array}$ & $\begin{array}{c}\text { FDP } \\
(\%)\end{array}$ \\
\hline ERM1 & 0.5 & 15 & $21.1 \mathrm{a}$ & $4.1 \mathrm{a}$ & $15.8 \mathrm{a}$ & $82.0 \mathrm{a}$ \\
ERM2 & 0.5 & 30 & $11.4 \mathrm{~b}$ & $2.4 \mathrm{~b}$ & $3.5 \mathrm{~b}$ & $32.0 \mathrm{~b}$ \\
ERM3 & 1 & 15 & $9.2 \mathrm{~b}$ & $2.3 \mathrm{~b}$ & $9.1 \mathrm{ab}$ & $38.0 \mathrm{~b}$ \\
ERM4 & 1 & 30 & $21.3 \mathrm{a}$ & $4.8 \mathrm{a}$ & $15.5 \mathrm{a}$ & $82.0 \mathrm{a}$ \\
\hline
\end{tabular}

Data recorded after 4 weeks of culture. Means with different letters within a column indicate significant differences (least significant difference, $P \leq 0.05$ ).

$\mathrm{MS}=$ Murashige and Skoog; FDP = fully developed plantlet; ERM = elongation/rooting media.

tamination was observed with garden soil and peatmoss as substrates, even with periodic benomyl (1 g. $\left.\mathrm{L}^{-1}\right)$ applications; meanwhile, when vermiculite was used, the contamination problem was absent (data not shown). On the other hand, no significant differences were observed in plant growth and survival among the doses of MS for ferti-irrigation (data not shown); therefore, $0.5 \times$ MS was selected to minimize costs.

A total of 50 FDPs were acclimated using vermiculite as substrate and $0.5 \times \mathrm{MS}$ as fertiirrigation solution (Fig. 1E). A 100\% plant survival rate was observed after 4 weeks. Plants were able to develop flowers after 2 weeks, and the fruits ripened (Fig. 1F) after 4 additional weeks. On average, 15 fruits per plant and 20 seeds per fruit were obtained with a germination rate of $100 \%$. This protocol has also been effective in the acclimatization of potato and tobacco plantlets in our laboratory; therefore, it may be useful in other plant species.

Gene transfer. Transient gusA expression was detected in leaf explants after $48 \mathrm{~h}$ of Agrobacterium cocultivation and $24 \mathrm{~h}$ of X-Gluc incubation (Fig. 2A) with efficiencies ranging from $68 \%$ to $100 \%$ (Table 3). Blue staining was not detected in non-infected leaves (Fig. 2B). When $\mathrm{PCM} 1$ was used during pre- and coculture,
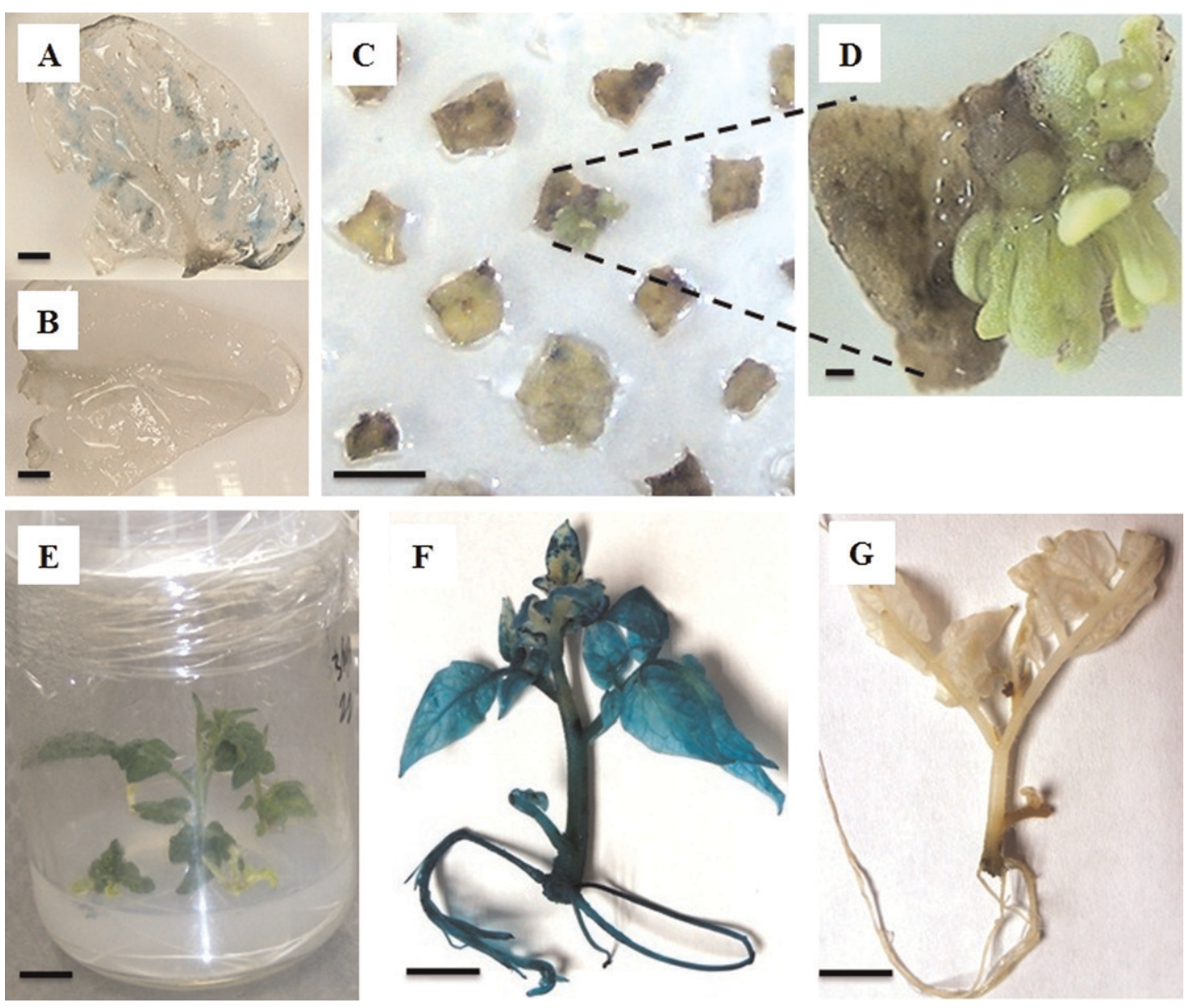

Fig. 2. Genetic transformation of tomato. (A) Transient gusA expression in leaf explant cocultured with Agrobacterium. (B) Wild-type explant as a negative control of gusA expression. (C) Shoot induction after 4 weeks in selective SIM4. (D) Amplified view of kanamycin-resistant shoots. (E) Putative transgenic plantlet after 2 weeks in selective ERM1. (F) Stable gusA expression in transgenic plantlet. (G) Wild-type plantlet as a negative control of gusA expression. Bars $=1 \mathrm{~cm}$, except for $\mathbf{A}, \mathbf{B}$, and $\mathbf{D}$, which are $0.1 \mathrm{~cm}$. SIM = shoot induction media; ERM = elongation $/$ rooting media. 
the Agrobacterium concentration had no significant effect on the percentage of explants with gusA expression, obtaining an average value of $70 \%$; meanwhile, when PCM2 was used, the Agrobacterium with $\mathrm{OD}_{600}$ of 0.5 and 0.8 gave significantly higher percentages of gusA-positive explants $(100 \%$ and $96 \%$, respectively) than that with $\mathrm{OD}_{600}$ of $0.2(68 \%)$. These results indicate that the growth regulators used in PCM2 (1 mg. $\mathrm{L}^{-1}$ BAP, $\left.0.1 \mathrm{mg} \cdot \mathrm{L}^{-1} \mathrm{NAA}\right)$ are more efficient than those in PCM1 $\left(2 \mathrm{mg} \cdot \mathrm{L}^{-1}\right.$ $\left.\mathrm{ZT}, 0.1 \mathrm{mg} \cdot \mathrm{L}^{-1} \mathrm{IAA}\right)$ for pre- and coculture steps and that higher Agrobacterium concentrations $\left(\mathrm{OD}_{600}=0.5\right.$ to 0.8$)$ are suitable for a high gus $A$ transient expression in tomato leaf explants. Because a high concentration of Agrobacterium can cause bacterial overgrowth problems and explants death during stable transformation (Dan et al., 2006), Agrobacterium $\mathrm{OD}_{600}$ of 0.5 was used for further experiments. It is worth mentioning that this gene transfer protocol eliminates the laborious preparation of Agrobacterium inoculums, including centrifugation steps. In addition, the feeder layers commonly used during coculture (Dan et al., 2006) were replaced here with the incorporation of AS to the medium, avoiding another time-consuming step.

Stable transformation. A total of 120 tomato leaf explants were pre-cultured in PCM2 for $48 \mathrm{~h}$, infected with Agrobacterium $\left(\mathrm{OD}_{600}=\right.$ 0.5 ) for $10 \mathrm{~min}$, and cocultured in PCM2 for $48 \mathrm{~h}$. After that, explants were washed five times ( 5 min each) with sterile distilled water containing $300 \mathrm{mg} \cdot \mathrm{L}^{-1} \mathrm{TM}$ and transferred to selective SIM4 (supplemented with $50 \mathrm{mg} \cdot \mathrm{L}^{-1}$ $\mathrm{KM}$ ). Shoot induction was observed after 4 weeks (Fig. 2C-D), and 44 differentiated shoots were obtained after 6 weeks of culture. The dose of TM (300 $\left.\mathrm{mg} \cdot \mathrm{L}^{-1}\right)$ used during washing and shoot induction in SIM4 effectively suppressed Agrobacterium growth, and it was no longer necessary to use it during rooting. Regenerated shoots were cultured in selective ERM1 (supplemented with 50 $\mathrm{mg} \cdot \mathrm{L}^{-1} \mathrm{KM}$ ) medium, from which 23 putative transformed plantlets were recovered (Fig. 2E). Histological analysis detected stable GUS expression in all tissues (leaf, stem, and root) of putative transformed plantlets (Fig. 2F), allowing us to confirm that they are not chimeras. GUS staining was not detected in tissues of non-transformed plants (Fig. 2G). Some of the GUS-positive plants were subjected to PCR analysis, through which the amplification of both the fragments of $982 \mathrm{bp}$ (gusA) and $341 \mathrm{bp}$ (CAMV 35S) were confirmed in all the putative transformed plants (Fig. 3A-B). Based on the number of Agro-infected explants and the regenerated PCR-confirmed plants, a transformation efficiency of $19.1 \%$ was achieved. This transformation efficiency allows the use of this protocol for research purposes, because transgenic plantlets can be easily propagated through axillary buds culture and then transferred to ex vitro conditions for fruit production. A $100 \%$ of plant survival rate and no phenotypic abnormalities were observed. Fruit and seed number from transgenic plants were sim-

Table 3. Effect of Agrobacterium concentration and culture media on transient gusA expression in tomato leaf explants.

\begin{tabular}{lcc}
\hline Culture media & $\begin{array}{c}\text { Agrobacterium } \\
\text { concn }\left(\mathrm{OD}_{600}\right)\end{array}$ & $\begin{array}{c}\text { Explants with transient } \\
\text { gusA expression }(\%)\end{array}$ \\
\hline PCM1 (2 mg. $\left.{ }^{-1} \mathrm{ZT}+0.1 \mathrm{mg} \cdot \mathrm{L}^{-1} \mathrm{IAA}\right)$ & 0.2 & $72.0 \mathrm{~b}$ \\
& 0.5 & $72.0 \mathrm{~b}$ \\
& 0.8 & $68.0 \mathrm{~b}$ \\
PCM2 (1 mg. $\left.{ }^{-1} \mathrm{BAP}+0.1 \mathrm{mg} \cdot \mathrm{L}^{-1} \mathrm{NAA}\right)$ & 0.2 & $68.0 \mathrm{~b}$ \\
& 0.5 & $100.0 \mathrm{a}$ \\
\end{tabular}

Data registered after $48 \mathrm{~h}$ of coculture with Agrobacterium and $24 \mathrm{~h}$ of incubation with X-Gluc. Means with different letters within a column indicate significant differences (least significant difference, $P \leq$ 0.05).

$\mathrm{PCM}=$ pre-culture media; $\mathrm{ZT}=$ zeatin; $\mathrm{BAP}=$ benzylaminopurine NAA $=$ naphthaleneacetic acid.

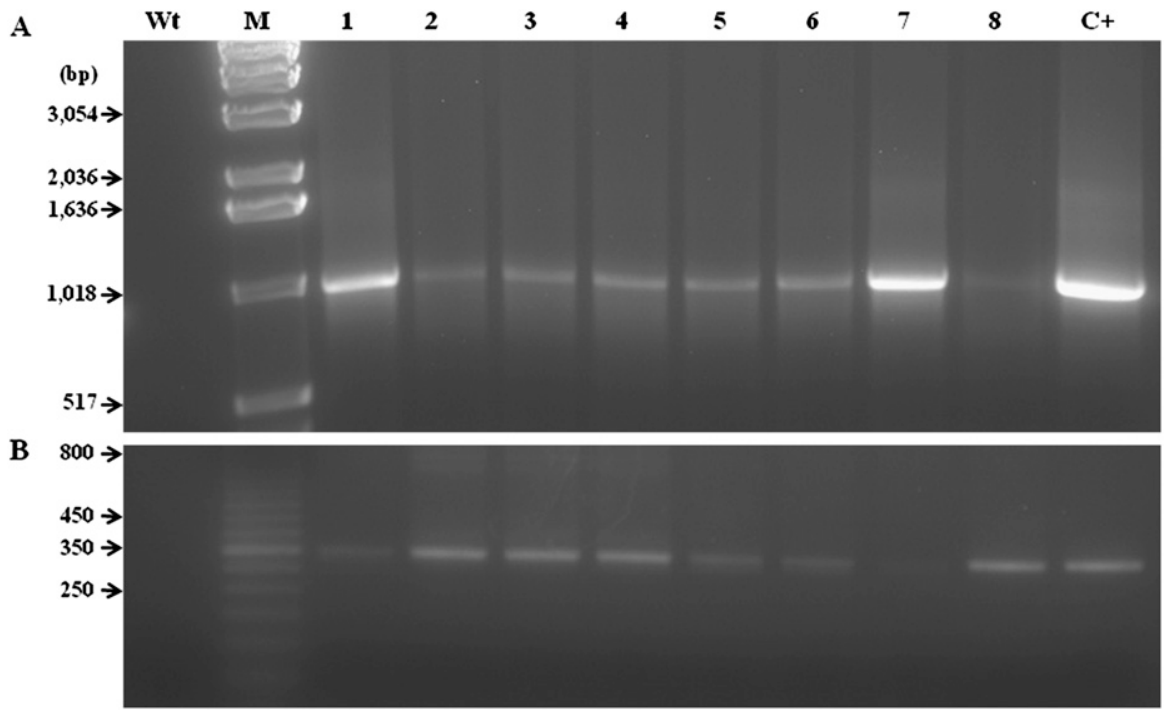

Fig. 3. DNA amplification of the gusA gene (A) and CaMV 35S promoter $(\mathbf{B})$ in transformed plants. Lanes 1 through 8 are independent transformed tomato lines. $\mathrm{Wt}=$ wild-type plant used as negative controls; $\mathrm{M}=$ molecular weight markers: 1-kb DNA ladder (A) and 50-bp DNA ladder (B), both of Invitrogen. $\mathrm{C}+$ : positive controls of pCAMBIA2301.

ilar to those previously determined for wildtype plants.

Park et al. (2003) reported stable transformation of tomato cv. Micro-Tom using an Agrobacterium suspension of $\mathrm{OD}_{600}=1.0$ with efficiencies of $10 \%, 15 \%$, and $20 \%$ for leaf, hypocotyl, and cotyledon explants, respectively. These explants were pre-cultured for $24 \mathrm{~h}$ in a medium similar to PCM2 (without AS) and cocultured for $72 \mathrm{~h}$ in the same medium. On the other hand, Dan et al. (2006) observed higher levels of $g f p$ transient expression in cotyledons of tomato cv. MicroTom as the Agrobacterium $\mathrm{OD}_{600}$ increased from 0.01 to 1.0 . However, the highest level of stable transformation $(20 \%)$ was achieved with low and intermediate $\mathrm{OD}_{600}(0.1$ and $0.5)$, whereas a high $\mathrm{OD}_{600}(1.0)$ caused an overgrowth of Agrobacterium and the death of explants. These were pre-cultured ( $24 \mathrm{~h})$ and cocultured $(48 \mathrm{~h})$ in a medium supplemented with feeder layer cells, which are used to produce phenolic compounds that promote infection of Agrobacterium by activating vir genes. Nevertheless, it has been shown that the simple addition of AS to pre- and coculture media can replace the use of feeder layers (Cortina and Culiáñez-Macia, 2004). On the other hand, Qiu et al. (2007) observed higher stable transformation efficiencies in cotyledons of tomato cv. Micro-Tom as Agrobacterium $\mathrm{OD}_{600}$ decreased, obtaining an efficiency of $20.8 \%$ with an $\mathrm{OD}_{600}$ of 0.2 in combination with a medium similar to PCM1 (without AS) for pre-culture $(24 \mathrm{~h})$ and coculture $(72 \mathrm{~h})$. In the same work, a transformation efficiency of $30.7 \%$ was obtained by using feeder layers during coculture, although the authors conclude that this strategy is very laborious to be used routinely.

The requirement of using hypocotyls or cotyledons as transformation explants represents a limitation, because only one or two explants can be obtained per seed, respectively, in comparison with $\approx 20$ leaf explants that can be obtained per plantlet. Thus, foliar explants from micropropagated plantlets can be used successfully for transformation purposes, avoiding seed dependency.

In conclusion, a fast, simple, and efficient transformation protocol for leaf explants of tomato cv. Micro-Tom was established, which relies on three culture media (PCM2, SIM4, and ERM1) with only one subculture during shoot induction and minimal Agrobacterium preparation before infection. In addition, 
a highly efficient acclimatization procedure was standardized. The complete protocol from infection to fruit production of transgenic plants can be accomplished in only 4 months, and it seems to be very useful for the analysis of transgenes of agronomical and nutraceutical interest in this convenient tomato cultivar.

\section{Literature Cited}

Bhatia, P., N. Ashwath, T. Senaratna, and D. Midmore. 2004. Tissue culture studies of tomato (Lycopersicon esculentum). Plant Cell Tissue Organ Cult. 78:1-21.

Cortina, C. and F.A. Culiáñez-Macia. 2004. Tomato transformation and transgenic plant production. Plant Cell Tissue Organ Cult. 76: 269-275.

Costa, M.G.C., F.T.S. Nogueira, M.L. Figueira, W.C. Otoni, S.H. Brommonschenkel, and P.R. Cecon. 2000. Influence of the antibiotic timentin on plant regeneration of tomato (Lycopersicon esculentum Mill.) cultivars. Plant Cell Rpt. 19:327-332.

Dan, Y., H. Yan, T. Munyikwa, J. Dong, Y. Zhang, and C.L. Armstrong. 2006. MicroTom-a highthroughput model transformation system for functional genomics. Plant Cell Rpt. 25:432-441.

Emmanuel, E. and A.A. Levy. 2002. Tomato mutants as tools for functional genomics. Curr. Opin. Plant Biol. 5:112-117.

FAOSTAT. 2011. FAO statistical database. 7 May 2011. <http://faostat.fao.org/>.

Frary, A. and J. Van Eck. 2004. Organogenesis from transformed tomato explants, p. 141-150. In: Peña, L. (ed.). Transgenic plants: Methods and protocols. Humana Press, Totowa, NJ.

García-Saucedo, P.A., M. Valdez-Morales, M.E. Valverde, A. Cruz-Hernández, and O. ParedesLópez. 2005. Plant regeneration of three Opuntia genotypes used as human food. Plant Cell Tissue Organ Cult. 80:215-219.

Gubis, J., Z. Lajchova, J. Farago, and Z. Jurekova. 2004. Effect of growth regulators on shoot induction and plant regeneration in tomato ( $\mathrm{LyCO}$ persicon esculentum Mill.). Biologia 59:405-408.

Herrera-Estrella, L., J. Simpson, and M. MartínezTrujillo. 2004. Transgenic plants: An historical perspective, p. 3-31. In: Peña, L. (ed.). Transgenic plants: Methods and protocols. Humana Press, Totowa, NJ.

Jefferson, R.A. 1987. Assaying chimeric genes in plants: The GUS gene fusion system. Plant Mol. Biol. Rpt. 5:387-405.

Ling, H.Q., D. Kriseleit, and M.W. Ganal. 1998. Effect of ticarcillin/potassium clavulanate on callus growth and shoot regeneration in Agrobacteriummediated transformation of tomato (Lycopersicon esculentum Mill.). Plant Cell Rpt. 17: 843-847.

Martínez-Pulido, C., I.S. Harry, and T.A. Torpe. 1992. Optimization of bud induction in cotiledonary explants of Pinus canariensis. Plant Cell Tissue Organ Cult. 29:247-255.

McCormick, S., J. Niedermeyer, J. Fry, A. Barnason, R. Horsch, and R. Fraley. 1986. Leaf disc transformation of cultivated tomato (L. esculentum) using Agrobacterium tumefaciens. Plant Cell Rpt. 5:81-84.

Meissner, R., Y. Jacobson, S. Melamed, S. Levyatuv, G. Shalev, A. Ashri, Y. Elkind, and A. Levy. 1997. A new model system for tomato genetics. Plant J. 12:1465-1472.

Mensuali-Sodi, A., M. Panizza, and F. Tognoni. 1995. Endogenous ethylene requirement for adventitious root induction and growth in tomato cotyledons and lavandin microcuttings in vitro. Plant Growth Regulat. 17:205-212.

Murashige, T. and F. Skoog. 1962. A revised medium for rapid growth and bioassays with tobacco tissue cultures. Physiol. Plant. 15:472-497.
Park, S.H., J.L. Morris, J.E. Park, K.D. Hirschi, and R.H. Smith. 2003. Efficient and genotypeindependent Agrobacterium-mediated tomato transformation. J. Plant Physiol. 160:12531257.

Pospíšilová, J., I. Tichá, P. Kadleček, D. Haisel, and S. Plzáková. 1999. Acclimatization of micropropagated plants to ex vitro conditions. Biol. Plant. 42:481-497.

Qiu, D., G. Diretto, R. Tavarza, and G. Giuliano. 2007. Improved protocol for Agrobacterium mediated transformation of tomato and production of transgenic plants containing carotenoid biosynthetic gene CsZCD. Sci. Hort. 112:172175.

Rao, K.V., K. Kiranmayee, U. Pavan, T. Jaya Sree, A.V. Rao, and A. Sadanandam. 2005. Induction of multiple shoots from leaf segments, in vitro-flowering and fruiting of a dwarf tomato (Lycopersicon esculentum). J. Plant Physiol. 162:959-962.

Rivera-López, J. 2011. Establecimiento de un sistema de cultivo in vitro de tejidos y transformación genética de papa (Solanum tuberosum L.) cv. Alpha. PhD thesis, Universidad Autónoma de Sinaloa, México.

Sun, H.J., S. Uchii, S. Watanabe, and H. Ezura. 2006. A highly efficient transformation protocol for Micro-Tom, a model cultivar for tomato functional genomics. Plant Cell Physiol. 47:426-431.

Valdez-Ortiz, A., S. Medina-Godoy, M.E. Valverde, and O. Paredes-López. 2007. A transgenic tropical maize line generated by the direct transformation of the embryo-scutellum by $A$. tumefaciens. Plant Cell Tissue Organ Cult. 91:201-214.

Vanegas, P.E., A. Cruz-Hernández, M.E. Valverde, and O. Paredes-López. 2002. Plant regeneration via organogenesis in marigold. Plant Cell Tissue Organ Cult. 69:279-283. 